\title{
Recall order determines the magnitude of directed forgetting in the within-participants list method
}

\author{
JONATHAN M. GOLDING and LAWRENCE R. GOTTLOB \\ University of Kentucky, Lexington, Kentucky
}

\begin{abstract}
In three experiments, we investigated the effect of recall order on directed forgetting when the within-participants list method is used. Experiment 1 showed that participants tend to recall to-beremembered $(\mathrm{R})$ items before to-be-forgotten $(\mathrm{F})$ items when they can recall items in any order. In Experiment 2, recall order was manipulated (F-R or R-F). The results showed that only the R-F order led to directed forgetting. Finally, in Experiment 3, recall order was also manipulated, and half of the participants were explicitly instructed to use a relational strategy when both $\mathrm{F}$ and $\mathrm{R}$ items were presented. Again, only the R-F order led to directed forgetting. These results demonstrate that directed forgetting under the list method hinges on the output order in which participants recall the $\mathrm{F}$ and $\mathrm{R}$ information. Thus, output order should be taken into account by researchers investigating specific mechanisms that lead to directed forgetting.
\end{abstract}

Directed forgetting is a robust cognitive finding that has been investigated for over 30 years (for recent reviews, see Bjork, 1998; Golding \& Long, 1998; MacLeod, 1998). In studies of this phenomenon, individuals are presented with some information that is subsequently designated as to be forgotten (F) or irrelevant through the use of a forget cue. Other information is designated as to be remembered $(\mathrm{R})$ or relevant. The effectiveness of the forget cue is shown by lower memory for the F information and higher memory for the $\mathrm{R}$ information than when the forget cue is not presented. Moreover, research has indicated that the lower recall of the $\mathrm{F}$ information is not the result of demand characteristics (i.e., participants simply withholding F items during memory tasks; see Bjork \& Woodward, 1973; MacLeod, 1999; Woodward $\&$ Bjork, 1971). It has been suggested that these forget cues serve to reduce proactive interference and thus allow for the adaptive use of memory (see Anderson \& Milson, 1989; Kraemer \& Golding, 1997).

Research on directed forgetting has primarily used two presentation methods: the item method (where a memory cue is presented following each item) and the list method (where a memory cue is presented following a list of items; see MacLeod, 1998). In the list method, F and $\mathrm{R}$ words are presented in separate lists, and the $\mathrm{F}$ instruction is given (typically) after the first list (e.g., Bjork, 1972; Geiselman, Bjork, \& Fishman, 1983). List method directed forgetting can be operationalized in two ways, corresponding to two different experimental designs. In a within-participants design, the goal is to examine an in-

We thank Lauren Recchiuti and Corey Fannin for their help in running the experiments. Correspondence concerning this article should be addressed to J. M. Golding, Department of Psychology, University of Kentucky, Lexington, KY 40506-0044 (e-mail: golding@uky.edu). dividual's performance on a (first) F list, as compared with a (second) R list. MacLeod (1998, p. 5) labels this the "R-F difference." Alternatively, one can use a betweenparticipants design in which the performance of a group receiving an $\mathrm{F}$ instruction ( $\mathrm{F}$ list followed by $\mathrm{R}$ list) is compared with a group that does not receive this instruction ( $\mathrm{R}$ list followed by $\mathrm{R}$ list). In this design, performance on the F list for the forget group is compared with that on the first $\mathrm{R}$ list for the remember group, and performance on the $\mathrm{R}$ list for the forget group is compared with that on the second $\mathrm{R}$ list for the remember group. MacLeod $(1998$, p. 5) refers to the between-participants design as a "cost/benefits analysis." The present study was designed to use the within-participants list method in order to explore a possible mechanism that may also exist in other directed-forgetting designs: the effect of recall order.

The results from list method studies (both within- and between-participants methods) have often been attributed to retrieval inhibition. For example, Geiselman et al. (1983) found directed forgetting of both intentionally and incidentally learned words from List 1 and concluded that access to all of the List 1 items was inhibited by the forget instruction (see also Basden, Basden, \& Gargano, 1993; Bjork, 1989, 1998). Further support for retrieval inhibition in the list method comes from a categorization task used by Geiselman et al. to determine whether participants could correctly judge whether a word that was recalled was an $\mathrm{F}$ or an $\mathrm{R}$ word. It was shown that participants had a difficult time categorizing $\mathrm{F}$ words as $\mathrm{F}$ words, but not categorizing $\mathrm{R}$ words as $\mathrm{R}$ words; it appeared that retrieval routes to the $\mathrm{F}$ words were disrupted. Basden et al. (1993) argued that relational processing is associated with the list method, in that participants are presumably trying to relate the words to each other and encode the items together, which may facilitate efforts to inhibit a list of $\mathrm{F}$ words. 
Recently, researchers have questioned retrieval inhibition as the sole mechanism for directed forgetting. It has lately been suggested that other mechanisms could also be implicated, including context change (Sahakyan $\&$ Kelley, 2002) and disrupted retrieval (Basden, Basden, \& Morales, 2003; see also MacLeod, Dodd, Sheard, Wilson, \& Bibi, 2003). In addition, a complete account of directed forgetting should identify potential sources of variance introduced by the experimental procedure itself. Recall order is one such variable. In the present study, we tried to determine whether directed forgetting in the list method is at least partially attributable to the order of recall of the $\mathrm{F}$ and $\mathrm{R}$ items and is not just the result of instructions to forget. Such a finding has important implications, for it could call into question whether the magnitude of the effects found in previous list method studies were completely attributable to directed forgetting.

To investigate the effect of recall order on directed forgetting, one must take a step back to think about the list method itself. After the F and the R lists have been presented, participants in the F condition must (typically, after a delay) recall both the $\mathrm{F}$ and the $\mathrm{R}$ lists. The participants are told to recall all of the items, including those they were instructed to forget. In most directed forgetting studies in which the list method has been used, the order in which the F and $\mathrm{R}$ items should be recalled has not been specified and has not been measured. By allowing participants to recall the $\mathrm{F}$ and $\mathrm{R}$ words in any order, it is possible that the words are recalled in a random order. It is also possible, however, that participants choose a specific recall order, such as $\mathrm{R}-\mathrm{F}$ or $\mathrm{F}-\mathrm{R}$. For example, because the $\mathrm{R}$ list is almost always presented after the $\mathrm{F}$ list, participants may take advantage of recency and start their recall with the R words, followed by the F words. This recall order would lead to apparent forgetting of the F words, but it might have more to do with output interference than with retrieval inhibition per se. That is, it might be that the $\mathrm{R}$ items are recalled well because they are recalled first (and hence, have very little proactive interference) and that the $\mathrm{F}$ items are recalled poorly because of the increasing proactive interference at output. Consequently, participants who use an F-R recall order may show an apparent reduction of directed forgetting.

The possibility that recall order affects directed forgetting has received some attention, but only by those who have used the between-participants list method. They have either measured output order or manipulated recall order directly. Geiselman et al. (1983, Experiments 1-3) correlated the order in which the F words were recalled with the order in which these were presented. They found that recall order and presentation order for the F words were "relatively unrelated" (p. 64), in contrast to the $\mathrm{R}$ words for the group receiving the forget cue; for participants instructed to remember both lists, correlations were highly significant across both lists. These measures, however, appear to measure the presentation-order/output-order correlation only within a particular F or R list. There was no measure of whether, across the lists, the participants chose to recall $\mathrm{F}$ or $\mathrm{R}$ words first or last. In their Experiment 4, Geiselman et al. had the participants recall the words in a specified order (F-R or R-F). They reported no interaction of this manipulation with whether the participants had to forget List 1 or not. It is difficult to accurately assess these results, however, because the recall order results were not presented.

Recall order has also been examined by Sahakyan, using the between-participants list method. In three of these studies (Sahakyan \& Delaney, 2003; Sahakyan, Delaney, \& Kelley, 2004; Sahakyan \& Kelley, 2002), participants were asked to recall the presented words, using a List 1 -List 2 order (the List 2 -List 1 order was not included in the design). There was evidence of directed forgetting in each of these studies. In addition, Sahakyan and Kelley found that participants made very few intrusions of $\mathrm{R}$ items when recalling the $\mathrm{F}$ list and vice versa (i.e., high categorization performance). In a very recent study (Sahakyan, 2004), participants were presented with three lists of $F$ or $R$ words ( F-R-R, R-F-R, or $\mathrm{R}-\mathrm{R}-\mathrm{R})$. Following presentation, the participants had to recall the words using a List $1-$ List $2-$ List 3 or a List 2List 1-List 3 order. This study, however, was inconclusive regarding the effects of recall order; apparently, there were no effects, because none involving recall order was reported.

The previous studies in which recall order has been investigated cast doubt on it as an influence on directed forgetting. However, the absence of data (Geiselman et al., 1983; Sahakyan, 2004), lack of complete recall order manipulation (Sahakyan \& Delaney, 2003; Sahakyan et al., 2004; Sahakyan \& Kelley, 2002), and lack of full data analysis (Sahakyan, 2004) make the effect of recall order equivocal. In addition, the use of the between-participants list method may obscure recall order effects if they exist, because manipulation of recall order adds a third factor to an already complex nested (repeated measures) design. Experiments in which recall order is fully manipulated may lack the power to detect the three-way interactions that would confirm the influence of recall order on directed forgetting. A more powerful test can be constructed using the within-participants list method, in which recall order is added as a factor. Effects of recall order on directed forgetting, in this design, would be detected as two-way interactions between type of list (F or R; a within-participants factor) and recall order (F-R or R-F; a between-participants factor).

In the present study, recall order and directed forgetting were investigated in several experiments, using the within-participants list method. In Experiment 1, the participants followed the typical within-participants list method procedure. Most important, at recall, the participants were not told in which order to recall the items. It was predicted that there would be a bias toward an R-F recall order and that this order would be associated with directed forgetting. In Experiment 2, recall order was 
systematically manipulated; half of the subjects received an $\mathrm{R}-\mathrm{F}$ order, and half received an $\mathrm{F}-\mathrm{R}$ order. Because of presumed output interference, the results might lead to an interaction in which the $\mathrm{R}-\mathrm{F}$ recall order leads to directed forgetting but the F-R recall order does not lead to directed forgetting.

In Experiment 2, categorization performance was also measured to determine whether recall order impacts the ability to correctly identify whether a recalled word was F or R. It was predicted (on the basis of Geiselman et al., 1983) that output interference would lead to poorer categorization performance for $\mathrm{F}$ words in the $\mathrm{R}-\mathrm{F}$ recall condition. Conversely, in the $\mathrm{F}-\mathrm{R}$ recall condition, $\mathrm{F}$ words would be categorized relatively well, because there would be little output interference. Finally, in Experiment 3 , recall order again was manipulated, along with the strategy the participants used to process the words at encoding, in order to determine whether greater relational processing would interact with recall order. On the basis of Basden et al. (1993), if participants related words together, retrieval inhibition should be obtained regardless of recall order. However, it was possible that any impact of recall order would override the influence of processing strategy.

\section{EXPERIMENT 1}

\section{Method}

Participants. The participants included 20 undergraduates from the University of Kentucky, who received partial course credit for participating.

Design. The experiment manipulated a single within-participants variable (word type) with two levels: $F$ and $R$ words. The primary dependent measure was recall of the $\mathrm{F}$ and $\mathrm{R}$ words.

Materials. The materials included a list of 20 unrelated concrete words: pawn, fork, jail, jug, pants, tent, lung, floss, seesaw, robot, noose, giraffe, raccoon, windpipe, wool, yeast, gown, beaker, ramp, and porpoise. The list of words was split into two parts. For each participant, half of the list was presented as R, whereas the other half of the list constituted the F words, and vice versa.

Procedure. The participants were initially informed via the computer that they were participating in a memory experiment in which words would be presented on PC computers. They were told that words would be presented for $5 \mathrm{sec}$ apiece and that there would be a 1-sec blank interval between words. The words were then presented (12-point white text in the center of a black screen). When the participants completed List 1, they were told via the computer the following (from Basden et al., 1993; Geiselman et al., 1983):

What you have done so far has been practice; therefore, you should forget about all of the to-be-learned words that have been presented. The list you will see next is the one we want you to remember, so forget the practice list and concentrate on this new list.

This instruction stayed on the screen for $15 \mathrm{sec}$. The second list was then presented. After the second list was presented, the participants engaged in a distractor task for 2 min (drawing and labeling a map of the United States) to eliminate any short-term memory effects. Following this task, the participants were asked to write down all of the words that they had been presented, regardless of the instruction in the middle of the list. They were given 4 min to recall the words. This time frame was based on extensive pilot testing that indicated that 2 min per list were required for participants to exhaust their ability to recall words.

\section{Results and Discussion}

A repeated measures analysis of variance (ANOVA) was conducted on the number of $\mathrm{R}$ and $\mathrm{F}$ words correctly recalled (word type). This analysis yielded a significant main effect of word type $\left[F(1,19)=4.43, M S_{\mathrm{e}}=0.03\right.$, $p<.05]$. The participants recalled a higher proportion of $\mathrm{R}$ words $(M=.45, S D=.18)$ than of $\mathrm{F}$ words $(M=.34$, $S D=.45)$. A correlation was computed on the serial position of each word on the recall list and whether a word was presented as F or R. If the participants tended to recall $\mathrm{R}$ words first, this correlation should be negative, because the $\mathrm{R}$ words were presented as the second list. The correlation confirmed this prediction $[r(158)=$ $-.23, p<.01]$. It should also be noted that the majority $(N=14)$ of the 20 participants $(70 \%)$ started their recall with an R word. A Mann-Whitney $U$ statistic (Marasciulo \& McSweeney, 1977) on the recall order, which measures the serial recall position of the $\mathrm{F}$ and $\mathrm{R}$ words, also indicated that $60 \%$ of the participants showed a bias toward recalling $\mathrm{R}$ words before $\mathrm{F}$ words. These results indicate that, given free choice, the majority of participants will start their recall with $\mathrm{R}$ words and that this choice will typically lead to directed forgetting. What will happen if participants do not have a choice on the order of recall, but this order is set for them? This question was addressed in Experiment 2.

\section{EXPERIMENT 2}

In this experiment, recall order was manipulated. Half of the participants had the recall order F-R, whereas the other half had the recall order R-F. On the basis of the logic presented earlier concerning output interference and the results from Experiment 1, it should be the case that the R-F recall order will lead to greater directed forgetting than the $\mathrm{F}-\mathrm{R}$ recall order. This prediction would manifest itself in a significant word type $\times$ recall order interaction. In addition, the later recall of $F$ words in the $\mathrm{R}-\mathrm{F}$ condition should lead to lower categorization performance for $\mathrm{F}$ words. That is, when the participants were asked to recall $\mathrm{R}$ words, they should recall only $\mathrm{R}$ words, and not $\mathrm{F}$ words, whereas recall for $\mathrm{F}$ words should contain a relatively high number of $\mathrm{R}$ contaminants. Once again, a significant word type $\times$ recall order interaction for this dependent variable would be predicted.

\section{Method}

Participants. The participants included 40 undergraduates from the University of Kentucky. They received partial course credit for participating. None of these individuals had participated in Experiment 1 .

Design. The experiment consisted of a 2 (word type) $\times 2$ (recall order) mixed factors design. The within-participants factor of word type had two levels ( $\mathrm{R}$ and $\mathrm{F}$ words), and the between-participants factor of recall order had two levels ( $\mathrm{R}-\mathrm{F}$ and $\mathrm{F}-\mathrm{R})$. The primary dependent measure was recall of the $\mathrm{F}$ and $\mathrm{R}$ words. A secondary measure was whether a recalled word was categorized correctly as an $\mathrm{F}$ or an $\mathrm{R}$ word.

Materials and Procedure. The same materials and procedure were used as in Experiment 1, except that, at recall, half of the par- 
ticipants were initially instructed to recall the words from List 1 (i.e., the words they had been instructed to forget). This instruction was written at the top of their recall sheet. After $2 \mathrm{~min}$, these participants were then asked to recall the words from List 2 (i.e., the R words). Again, the recall list instruction was written at the top of their recall sheet. The other half of the participants received the opposite recall order $(\mathrm{R}-\mathrm{F})$.

\section{Results and Discussion}

Correct recall. Consistent with most directed forgetting studies, any word that was recalled was scored as correct even if it was recalled on the opposite list. For example, an $\mathrm{F}$ word recalled on the $\mathrm{R}$ recall sheet was scored as a correctly recalled $\mathrm{F}$ word. However, this $\mathrm{F}$ word would be scored as an incorrect categorization. An initial examination of recall was conducted to determine whether the participants always began their recall of the $\mathrm{F}$ words and the $\mathrm{R}$ words with an appropriate word. For the $\mathrm{F}-\mathrm{R}$ condition, this was always the case. For the $\mathrm{R}-\mathrm{F}$ condition, there were 3 participants who began their $\mathrm{R}$ list recall with an $\mathrm{F}$ word and 3 participants who began their $\mathrm{F}$ list recall with an $\mathrm{R}$ word.

Next, a 2 (word type) $\times 2$ (recall order) mixed factors ANOVA was conducted on the proportions of $\mathrm{R}$ and $\mathrm{F}$ words recalled. This analysis yielded a significant word type $\times$ recall order interaction $\left[F(1,38)=6.00, M S_{\mathrm{e}}=\right.$ $0.04, p<.05]$. As can be seen in Table 1 , the participants in the $\mathrm{R}-\mathrm{F}$ condition showed evidence of directed forgetting. Recall of $\mathrm{F}$ words was lower than recall of $\mathrm{R}$ words $[t(19)=3.23, p<.01]$. Conversely, there was no evidence of directed forgetting for the $\mathrm{F}-\mathrm{R}$ condition. In fact, recall of $\mathrm{F}$ words was (nonsignificantly) higher than recall of $\mathrm{R}$ words $[t(19)<1]$. Also, recall of $\mathrm{F}$ words was higher in the $\mathrm{F}-\mathrm{R}$ condition than in the $\mathrm{R}-\mathrm{F}$ condition $[t(38)=2.02, p=.05]$, but recall of the $\mathrm{R}$ words did not differ significantly across the two recall order conditions $[t(38)=1.23, p=.27]$. It should be noted that, consistent with the above analysis, only $40 \%$ of the participants in the $\mathrm{F}-\mathrm{R}$ condition showed evidence of directed forgetting (i.e., $\mathrm{R}>\mathrm{F}$ ), as compared with $75 \%$ of the participants in the $\mathrm{R}-\mathrm{F}$ condition $\left[\chi^{2}(1)=5.01, p<.05\right]$.

Categorization. For each participant, $\mathrm{F}$ and $\mathrm{R}$ categorization scores were calculated. For F words, this score was correct $\mathrm{F}$ categorizations (i.e., recalling an $\mathrm{F}$ word as an $\mathrm{F}$ word) divided by the total number of $\mathrm{F}$ words re-

Table 1

Experiment 2: Proportions Correct for Forget (F) and Remember (R) Words (With Standard Deviations) as a Function of Recall Order

\begin{tabular}{cccccc}
\hline & \multicolumn{2}{c}{ F Words } & & \multicolumn{2}{c}{ R Words } \\
\cline { 2 - 3 } \cline { 5 - 6 } Recall Order & $M$ & $S D$ & & $M$ & $S D$ \\
\hline \multirow{2}{c}{ Recall } & & & \\
R-F & .40 & .17 & .52 & .23 \\
F-R & .52 & .23 & .49 & .26 \\
& \multicolumn{2}{c}{ Categorization } & & \\
R-F & .45 & .40 & .93 & .19 \\
F-R & .92 & .15 & .93 & .14 \\
\hline
\end{tabular}

called. For $\mathrm{R}$ words, this score was correct $\mathrm{R}$ categorizations divided by the total number of $\mathrm{R}$ words recalled. A 2 (word type) $\times 2$ (recall order) mixed factors ANOVA was conducted on the proportions of $\mathrm{R}$ and $\mathrm{F}$ words correctly categorized. This analysis yielded a significant main effect of word type $\left[F(1,38)=23.83, M S_{\mathrm{e}}=0.05\right.$, $p<.01]$.

The main effect was qualified by a significant word type $\times$ recall order interaction $\left[F(1,38)=22.95, M S_{\mathrm{e}}=\right.$ $0.05, p<.01]$. As can be seen in Table 1, only the participants in the R-F condition had a problem categorizing F words. Follow-up comparisons indicated that categorization of $\mathrm{F}$ words in the $\mathrm{R}-\mathrm{F}$ recall order condition was lower than categorization of $\mathrm{R}$ words in this condition $[t(19)=5.38, p<.001]$. For the $\mathrm{F}-\mathrm{R}$ recall order, categorization of $\mathrm{F}$ and $\mathrm{R}$ words was not reliably different $[t(19)<1]$. Finally, $\mathrm{F}$ words in the $\mathrm{R}-\mathrm{F}$ recall order condition were not categorized as well as $\mathrm{F}$ words in the $\mathrm{F}-\mathrm{R}$ recall order condition $[t(38)=4.88, p<.01]$. The categorization of $\mathrm{R}$ words was the same in the R-F condition and the $\mathrm{F}-\mathrm{R}$ condition $[t(38)<1]$.

These results indicate the important role that recall order can play in directed forgetting, using the list method. Only when the participants initially recalled $\mathrm{R}$ words was there evidence of directed forgetting in the form of higher recall for $\mathrm{R}$ words than for $\mathrm{F}$ words. In this way, the present results support the findings of Experiment 1 that beginning recall with $\mathrm{R}$ words leads to some degree of output interference for $\mathrm{F}$ words. The absence of a crossover interaction (e.g., $\mathrm{R}>\mathrm{F}$ for the $\mathrm{R}-\mathrm{F}$ group and $F>\mathrm{R}$ for the $\mathrm{F}-\mathrm{R}$ group) indicates that the results likely were due not only to this interference. Still, the findings in Experiment 2 raise questions about whether previous directed forgetting studies in which the list method has been used have shown forgetting due to retrieval inhibition (e.g., Basden et al., 1993) or whether the results were due to a methodological artifact.

\section{EXPERIMENT 3}

In Experiment 3, we continued to investigate the impact of recall order on directed forgetting when the list method is used, by examining the possibility that the results of the earlier experiments were influenced by how the participants processed the words during presentation. Specifically, as was stated earlier, during list method presentation, participants are assumed to process the words in a relational manner (e.g., Basden et al., 1993). That is, as each word in a list is presented, it is related to the other words in the list. With regard to F words, relating words makes inhibiting or blocking access to the related group of words much easier than would be the case if the words were processed in a distinctive or one-byone fashion. It is interesting, however, that although the list method of presentation has been assumed to encourage relational processing, there have been no explicit instructions to participants to use such processing in previous directed forgetting research nor any measure (even 
self-reporting) of whether relational processing has been employed. Thus, it is not clear whether participants actually use such processing and whether such processing leads to retrieval inhibition.

In this experiment, the participants were given explicit instructions to either relate words together or not. In addition, the recall order manipulation used in Experiment 2 was included in the design. It was possible that instructions to relate words would be the catalyst for retrieval inhibition and that this might interact with recall order. Thus, it might be that participants who received explicit relate instructions would show greater directed forgetting than participants who did not. However, it was also possible that relational processing would have no effect on the retrieval of $\mathrm{F}$ and $\mathrm{R}$ items from memory.

\section{Method}

Participants. The participants included 80 undergraduates from the University of Kentucky. They received partial course credit for participating. None of these individuals had participated in Experiment 1 or 2 .

Design. The experiment consisted of a 2 (word type) $\times 2$ (recall order) $\times 2$ (relate) mixed factors design. Word type and recall order had the same levels as in Experiment 2. Relate had two betweenparticipants levels: explicit instructions to relate words together as they were presented or no such instructions. The same dependent measures were used as in Experiment 2.

Materials and Procedure. The same materials and procedure were used as in the previous experiments, except that half of the participants were given the following instructions prior to the words being presented:

To remember the words we would like you to try a specific memory strategy. We would like you to relate the words together. You can do this by seeing how the words relate to one another. You might also try putting the words together to make a story or think about the items described by the words as part of a picture.

To determine the impact of the instructions above, the participants were asked at the end of the experiment how they had tried to learn both the $\mathrm{F}$ and the $\mathrm{R}$ words.

\section{Results and Discussion}

The results showed that the participants followed the instructions. Of the 40 participants instructed to use relational processing, $33(83 \%)$ stated that they had used some type of relational strategy (e.g., relating the words together in a story) when learning both the $\mathrm{F}$ and the $\mathrm{R}$ words. However, for the participants given no relational processing instruction, only 17 of the 40 participants $(43 \%)$ had used some type of relational strategy when learning both the $\mathrm{F}$ and the $\mathrm{R}$ words. The instructions influenced the relational strategies $\left[\chi^{2}(1)=13.65, p<\right.$ $.001]$.

Correct recall. Once again, an initial examination of recall was conducted to determine whether the participants always began their recall of the $F$ words and the $R$ words with an appropriate word. For the F-R condition, this was always the case. For the R-F condition, there was 1 participant who began his initial list recall with a word from the inappropriate list.
A 2 (word type) $\times 2$ (recall order) $\times 2$ (relate) mixed factors ANOVA was conducted on the proportion of $\mathrm{R}$ and $\mathrm{F}$ words recalled. (Again, any word recalled was scored as correct even if it was recalled on the opposite list.) This analysis yielded a significant main effect of word type $\left[F(1,76)=6.25, M S_{\mathrm{e}}=0.05, p<.05\right]$. This main effect was qualified by a significant word type $X$ recall order interaction $\left[F(1,76)=12.05, M S_{\mathrm{e}}=0.05\right.$, $p<.01]$. As can be seen in Table 2, this interaction was the result of directed forgetting for the R-F recall order, but no directed forgetting for the F-R recall order-the same pattern as in Experiment 2. Follow-up comparisons showed that for the $\mathrm{R}-\mathrm{F}$ condition, recall of $\mathrm{R}$ words was higher than recall of $\mathrm{F}$ words $[t(39)=4.30, p<.01]$. Conversely, for the $\mathrm{F}-\mathrm{R}$ condition, recall of $\mathrm{R}$ words was not reliably different from recall of $\mathrm{F}$ words $[t(39)<1]$. In addition, recall of $\mathrm{F}$ words was higher in the $\mathrm{F}-\mathrm{R}$ condition than in the $\mathrm{R}-\mathrm{F}$ condition $[t(78)=1.97, p=.05]$, and recall of the $\mathrm{R}$ words was greater in the $\mathrm{R}-\mathrm{F}$ condition than in the $\mathrm{F}-\mathrm{R}$ condition $[t(78)=2.41, p<.05]$. Only $52 \%$ of the participants in the F-R condition showed evidence of directed forgetting (i.e., $\mathrm{R}>\mathrm{F}$ ), as compared with $73 \%$ of the participants in the $\mathrm{R}-\mathrm{F}$ condition, although the difference was not significant $\left[\chi^{2}(1)=\right.$ $3.41, p<.07]$.

Like the results in Experiment 2, these results show the important role that recall order can play in directed forgetting, using the list method; there was directed forgetting only for the $\mathrm{R}-\mathrm{F}$ recall order. In addition, instructing the participants to use a mnemonic that stressed relating words together did not lead to either a main effect or an interaction with recall order.

Categorization. A 2 (word type) $\times 2$ (recall order) mixed factors ANOVA was conducted on the proportions of $\mathrm{R}$ and $\mathrm{F}$ words correctly categorized. As in Experiment 2 , this analysis yielded a significant main effect of word type $\left[F(1,75)=8.00, M S_{\mathrm{e}}=0.06, p<.01\right]$. This was qualified by a significant word type $\times$ recall order interaction $\left[F(1,75)=10.56, M S_{\mathrm{e}}=0.06, p<.01\right]$. As can be seen in Table 2, it was again the case that the lowest categorization score was for the participants in the $\mathrm{R}-\mathrm{F}$ condition categorizing $\mathrm{F}$ words. Follow-up comparisons indicated that categorization of $F$ words in the $\mathrm{R}-\mathrm{F}$

Table 2

Experiment 3: Proportions Correct for Forget (F) and Remember (R) Words (with Standard Deviations) as a Function of Recall Order

\begin{tabular}{clrlll}
\hline & \multicolumn{2}{c}{ F Words } & & \multicolumn{2}{c}{ R Words } \\
\cline { 2 - 3 } \cline { 5 - 6 } Recall Order & $M$ & $S D$ & & $M$ & $S D$ \\
\hline R-F & .43 & .25 & & .63 & .21 \\
F-R & .54 & .24 & .50 & .25 \\
& \multicolumn{2}{c}{ Recall } & & & \\
R-F & .76 & .35 & & 1.00 & .00 \\
F-R & .91 & .23 & .89 & .24 \\
\hline
\end{tabular}


condition was lower than that of $\mathrm{R}$ words $[t(77)=2.16$, $p<.05]$. Unlike in Experiment 2, the categorization of $\mathrm{R}$ words was reliably higher in the $\mathrm{R}-\mathrm{F}$ condition than in the $\mathrm{F}-\mathrm{R}$ condition $[t(77)=2.80, p<.01]$. Finally, for the $\mathrm{R}-\mathrm{F}$ condition, the categorization of $\mathrm{F}$ words was lower than the categorization of $\mathrm{R}$ words $[t(38)=4.17$, $p<.01]$, but for the $\mathrm{F}-\mathrm{R}$ condition, categorization scores for $\mathrm{R}$ words and $\mathrm{F}$ words were not reliably different $[t(39)<1]$.

\section{GENERAL DISCUSSION}

In the present study, we investigated the effect of recall order on directed forgetting, using the within-participants list method of presentation. There were several important findings from the three experiments in this study. First, in a typical within-participants list method directed forgetting experiment in which the participants were free to recall $\mathrm{F}$ and $\mathrm{R}$ words in any order, there was a tendency for participants to choose an R-F recall order. Second, when recall order was set for the participants as either $\mathrm{R}-\mathrm{F}$ or $\mathrm{F}-\mathrm{R}$, directed forgetting was found only with the $\mathrm{R}-\mathrm{F}$ recall order. Third, forcing the participants to use a relational strategy to process both $\mathrm{F}$ and $\mathrm{R}$ words did not overcome the impact of recall order on directed forgetting.

These results provide additional evidence that retrieval inhibition may not be the only mechanism underlying directed forgetting when the list method is employed. Previously, directed forgetting researchers have generally assumed that the list method encourages relational processing of the $\mathrm{F}$ and $\mathrm{R}$ lists of words and that this processing leads to retrieval inhibition of the F list. Such inhibition was thought to lead to lower $\mathrm{F}$ recall than $\mathrm{R}$ recall and an inability to categorize $\mathrm{F}$ words as $\mathrm{F}$ words, due to a disruption in retrieval routes (Geiselman et al., 1983). Although the present results do not rule out some role of retrieval inhibition or some other cognitive mechanism, especially given the absence of a crossover interaction in Experiments 2 and 3, they do indicate that in some previous directed forgetting research in which the list method has been used with unconstrained recall, the results have been affected by recall strategy (i.e., the order of recall).

What other cognitive mechanisms may lead to directed forgetting when the list method is used? Basden and Basden (1998; see also Basden et al., 2003) have investigated the strategy disruption hypothesis. This hypothesis states that the forget cue causes the participant to abandon his or her retrieval strategy based on List 1 items and to develop a revised retrieval strategy tailored to List 2 items. List 1 items, in this account, are not inhibited but suffer from reduced accessibility. Similarly, Sahakyan and Kelley's (2002) context change hypothesis states that directed forgetting is the by-product of changes in mental context between study of List 1 and study of List 2 . In fact, they have shown that it is possible to obtain effects similar to directed forgetting by having participants mentally change contexts, not by instructing them to for- get List 1 . It should be noted that the idea of a shifting strategy change or a context change is reminiscent of Wegner's $(1989,1994)$ research on thought suppression (see Golding \& Long, 1998, for a review). He found that participants had a difficult time suppressing the thought of a white bear until the participants were given a different item to think about (a red Volkswagen).

The interaction observed in both Experiments 2 and 3 showed that if the participants used an $\mathrm{R}-\mathrm{F}$ recall order, there was lower recall for $\mathrm{F}$ words than for $\mathrm{R}$ words. The $\mathrm{F}$ words were recalled last and may have suffered from output interference at recall. Besides lower F recall, the participants who recalled the $\mathrm{F}$ words last had a difficult time categorizing $\mathrm{F}$ words as $\mathrm{F}$ in Experiments 2 and 3. Conversely, the participants who had the $\mathrm{F}-\mathrm{R}$ recall order had a relatively easy time recalling the $\mathrm{F}$ words (i.e., not reliably different from the $\mathrm{R}$ words). These $\mathrm{F}$ words were recalled first and, thus, would not have been impacted by output interference. In addition, the participants who had the $\mathrm{F}-\mathrm{R}$ recall order had little difficulty categorizing the $\mathrm{F}$ words as $\mathrm{F}$.

It is important to note that the effect of recall order was present in all the experiments and that the pattern of results in Experiment 3 (i.e., the word type $\times$ recall order interaction) was not affected by explicit instructions to use a relational strategy when processing the $\mathrm{F}$ and $\mathrm{R}$ words. Previous explanations of how retrieval inhibition leads to directed forgetting when the list method is used have attributed an important role to relational processing. For example, Basden et al. (1993) argued that interrelating of $\mathrm{F}$ words during encoding facilitates retrieval inhibition of the entire block of related words. However, forcing the participants in Experiment 3 to relate the words in some manner (e.g., forming a story) did not have an effect independent of recall order. Such a result may also call into question the prominent role that has been ascribed to relational processing in list method directed forgetting.

Although directed forgetting was affected by recall order using the within-participants list method in the present study, there is evidence from between-participants list method studies that recall order does not affect directed forgetting. It would be easy to argue that slight methodological changes led to the difference between the studies. For example, Sahakyan and Kelley (2002) gave less time for recall of each list than we did in the present study. Perhaps their participants simply did not have enough time to recall more $F$ words. These words may have been less accessible initially but, with additional time, may have been recalled.

However, the seemingly contradictory results of the previous and the present list method studies may have also been due to differences in the operationalizing of directed forgetting. As was stated earlier, within-participants list method studies have been performed to investigate the $\mathrm{R}-\mathrm{F}$ difference; this subtype does not have a control group that receives $\mathrm{R}$ words on both List 1 and List 2 . When the $\mathrm{R}-\mathrm{F}$ difference is large, directed forgetting is said to be 
evident. In essence, the present results show that the R-F difference is large for the $\mathrm{R}-\mathrm{F}$ condition but that the $\mathrm{F}-\mathrm{R}$ condition does not lead to a difference. In contrast, between-participants list method studies focus on the differences in list recall between a group instructed to forget List 1 and remember List 2 (forget group) and a group that must remember both lists (remember group). There are two critical between-groups comparisons in this type of study: List 1 recall and List 2 recall. Directed forgetting is evident if recall on List 1 leads to the result that the forget group $<$ the remember group and, on List 2, the forget group $>$ the remember group. It is possible that if the present study had included a remember group, the results may have shown directed forgetting for both the R-F and the F-R conditions. That is, recall of List 1 by the remember group might have exceeded that of the forget group in both the R-F and the F-R condition, and recall of List 2 by the remember group might have been lower than that of the forget group. Thus, we can unequivocally state that recall order can affect the $\mathrm{R}-\mathrm{F}$ difference score when a within-participants list method experiment is employed and the critical measure is the $\mathrm{R}-\mathrm{F}$ difference; however, a more complete design that includes control groups (no forget instruction) may shed more light on the magnitude of the directed forgetting effect that can be attributed to recall order.

In summary, the present results indicate that recall order determines the magnitude of the directed forgetting effect in the within-participants list method. The participants had a tendency to choose the $\mathrm{R}-\mathrm{F}$ recall order, and only these participants showed a pattern of results consistent with directed forgetting (Experiment 1). In addition, when recall order was constrained (Experiments 2 and 3), only the R-F recall order led to directed forgetting. These results are consistent with the idea of output interference. That is, as words from a specific list are recalled, they interfere with recall of words from the other list. Additional research on output interference is needed to determine the parameters of this interference. For example, it is unclear whether the number of items to be initially recalled from a list or the time for recall affects output interference. The present results make clear that methodological considerations are important for researchers as they continue to investigate the specific mechanisms that lead to directed forgetting.

\section{REFERENCES}

Anderson, J. R., \& Milson, R. (1989). Human memory: An adaptive perspective. Psychological Review, 96, 703-719.

BASDEN, B. H., \& BASDEN, D. R. (1998). Directed forgetting: A contrast of methods and interpretations. In J. M. Golding \& C. M. MacLeod (Eds.), Intentional forgetting: Interdisciplinary approaches (pp. 59102). Mahwah, NJ: Erlbaum.
Basden, B. H., Basden, D. R., \& Gargano, G. (1993). Directed forgetting in implicit and explicit memory tests: A comparison of methods. Journal of Experimental Psychology: Learning, Memory, \& Cognition, 19, 603-616.

Basden, B. H., Basden, D. R., \& Morales, E. (2003). The role of retrieval practice in directed forgetting. Journal of Experimental Psychology: Learning, Memory, \& Cognition, 29, 389-397.

BJORK, R. A. (1972). Theoretical implications of directed forgetting. In A. W. Melton \& E. Martin (Eds.), Coding processes in human memory (pp. 217-235). Washington, DC: Winston.

BJORK, R. A. (1989). Retrieval inhibition as an adaptive mechanism in human memory. In H. L. Roediger III \& F. I. M. Craik (Eds.), Varieties of memory and consciousness: Essays in honour of Endel Tulving (pp. 309-330). Hillsdale, NJ: Erlbaum.

BJORK, R. A. (1998). Intentional forgetting in perspective. In J. M. Golding \& C. M. MacLeod (Eds.), Intentional forgetting: Interdisciplinary approaches (pp. 453-481). Mahwah, NJ: Erlbaum.

BJork, R. A., \& Woodward, A. E. (1973). Directed forgetting of individual words in free recall. Journal of Experimental Psychology, 99, 22-27.

Geiselman, R. E., BJork, R. A., \& Fishman, D. L. (1983). Disrupted retrieval in directed forgetting: A link with posthypnotic amnesia. Journal of Experimental Psychology: General, 112, 58-72.

GoLDING, J. M., \& LONG, D. L. (1998). There's more to intentional forgetting than directed forgetting: An integrative review. In J. M. Golding \& C. M. MacLeod (Eds.), Intentional forgetting: Interdisciplinary approaches (pp. 59-102). Mahwah, NJ: Erlbaum.

Kraemer, P. J., \& Golding, J. M. (1997). Adaptive forgetting in animals. Psychonomic Bulletin \& Review, 4, 480-491.

MacLeoD, C. M. (1998). Directed forgetting: The human memory literature. In J. M. Golding \& C. M. MacLeod (Eds.), Intentional forgetting: Interdisciplinary approaches (pp. 1-57). Mahwah, NJ: Erlbaum.

MacLeod, C. M. (1999). The item and list methods of directed forgetting: Test differences and the role of demand characteristics. Psychonomic Bulletin \& Review, 6, 123-129.

MACLEOD, C. M., DodD, M. D., Sheard, E. D., Wilson, D. E., \& BIBI, U. (2003). In opposition to inhibition. In B. H. Ross (Ed.), The psychology of learning and motivation (Vol. 43, pp. 163-214). San Diego: Academic Press.

Marasciulo, L. A., \& McSweeney, M. (1977). Nonparametric and distribution-free methods for the social sciences. Monterey, CA: Brooks-Cole.

SAHAKYAN, L. (2004). Destructive effects of "forget" instructions. Psychonomic Bulletin \& Review, 11, 555-559.

SaHAKYAN, L., \& Delaney, P. F. (2003). Can encoding differences explain the benefits of directed forgetting in the list method paradigm? Journal of Memory \& Language, 48, 195-206.

SaHaKyan, L., Delaney, P. F., \& Kelley, C. M. (2004). Self-evaluation as a moderating factor of strategy change in directed forgetting benefits. Psychonomic Bulletin \& Review, 11, 131-136.

SahaKyAn, L., \& Kelley, C. M. (2002). A contextual change account of the directed forgetting effect. Journal of Experimental Psychology: Learning, Memory, \& Cognition, 28, 1064-1072.

WEGNER, D. M. (1989). White bears and other unwanted thoughts. New York: Viking/Penguin.

WeGner, D. M. (1994). Ironic processes of mental control. Psychological Review, 101, 34-52.

WOODWARD, A. E., \& BJORK, R. A. (1971). Forgetting and remembering in free recall: Intentional and unintentional. Journal of Experimental Psychology, 89, 109-116.

(Manuscript received October 14, 2003; revision accepted for publication July 22, 2004.) 